\section{Discoversus \\ Published by DiscoverSys \\ Positive calretinin stain with immunohistochemistry in a 49 year-old female with cardiac myxoma: A case report}

\author{
I Gusti Ayu Sri Mahendra Dewi*
}

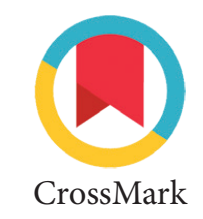

CrossMark

\title{
ABSTRACT
}

Background: Primary tumors of the heart are scarce. Cardiac myxoma is a primary benign heart tumor most often found with an incidence of $0.5-1.0$ cases per million population per year and $90 \%$ diagnosed in the fourth to seventh decades of life, rarely found in children. Cardiac myxoma is three times more common in women than in men. These tumors are mostly found in the left atrium.

Case description: Female, a 49-year-old patient, came with palpitations, shortness of breath, and weakness since the previous six months. On echocardiography, found a mass in the left atrium suspected of a left atrial myxoma. Surgery was performed, and the specimen was sent for histopathological examination. Macroscopically, the tumor mass shows an irregular shape, brownish color, and spongy consistency. Microscopic examination shows the tumor consisting of proliferation of spindle-shaped and stellate cells, with oval to round nuclei, eosinophilic cytoplasm, mostly scattered, some of which are arranged cord and nest, infiltrative between the myxoid stroma and partially surround small blood vessels to form a vasoformative ring. The specimen also contains the proliferation of blood vessels, extravasation of erythrocytes, and the distribution of inflammatory cells and hemosiderophages. The result of the immunohistochemical examination with calretinin was positive.

Conclusion: This case was concluded as cardiac myxoma based on clinical features, echocardiography, macroscopic, routine histopathological, and immunohistochemical examinations.
Department of Pathology Anatomy, Faculty of Medicine, Universitas Udayana/Sanglah General Hospital Denpasar-Bali

${ }^{*}$ Correspondence to:

I Gusti Ayu Sri Mahendra Dewi, Department of Pathology Anatomy, Faculty of Medicine, Universitas Udayana/Sanglah General Hospital Denpasar-Bali

mahendradewi@rocketmail.com

Received: 2020-09-05

Accepted: 2020-10-01

Published: 2020-10-03

Keywords: cardiac, calretinin, myxoma

Cite This Article: Dewi, I.G.A.S.M. 2020. Positive calretinin stain with immunohistochemistry in a 49 year-old female with cardiac myxoma: A case report. Intisari Sains Medis 11(3): 934-937. D0I: 10.15562/ism.v11i3.824

\section{INTRODUCTION}

Tumors in the heart are rare and are divided into primary tumors originating from the heart, and secondary or metastatic tumors from elsewhere. The prevalence of primary tumors In the heart ranged from 0.001 to $0.03 \%$ of all tumors. About $90 \%$ of primary tumors found are benign and the most common is myxoma $(50 \%-80 \%)$. Other benign primary tumors found in the heart include papillary fibroelastoma (PFE) (26\%), fibroma (6\%), lipoma (4\%), rhabdomyoma, hemangioma, and atrio ventricular node tumors.

Meanwhile, primary malignant tumors in the heart most often found are sarcoma (90\%) followed by lymphoma. The clinical features of primary tumors in the heart depend on the location, size, mobility, and infiltration of the tumor to the surrounding structures. More than $12 \%$ of primary heart tumors are usually asymptomatic and diagnosed at the time of routine examination, generally on an echocardiogram or postmortem examination. ${ }^{1,2}$

Cardiac myxoma is the most common benign primary heart tumor. These tumors are three times more common in women than men in the fourth to seventh decades of life and are rarely found in children. Cardiac myxoma can be found in all parts of the heart but is most often found in the left atrium in about $60-80 \%$ of cases. ${ }^{1,2,3}$

The next following reports a case of cardiac myxoma in the left atrium of a 49-year-old woman based on clinical features, radiological, macroscopic, microscopic, and immunohistochemical examinations. This case is reported because of its rare incident.

\section{CASE REPORT}

A 49-year-old female, Balinese, Indonesian patient to Sanglah General Hospital because of frequent palpitations and shortness of breath if heavy activities. The patient's previous history was often feeling tired and no chest pain, and never received medical treatment. There was no history of previous medical treatment. There was no family history and previous history of psychosocial disorders. An echocardiography examination was carried out and found a mass in the left atrium attached to the intra atrial septum, with a size of $4.97 \times 2.83 \mathrm{~cm}$. Clinically the patient was diagnosed with cardiac myxoma in the left atrium. Surgical resection was carried out, and then the tumor tissue was sent to the Anatomical 
Pathology Laboratory of Sanglah Hospital for histopathological examination. Informed consent is not required because it uses secondary data from paraffin block, H\&E slide and immunohistochemical stain.

On macroscopic examination, two pieces of tissue were received, the first tissue size was $4.5 \times$ $3.5 \times 1.2 \mathrm{~cm}$, and the second tissue size was $2.8 \times$ $2.3 \times 1 \mathrm{~cm}$, irregular shape, brownish-white with a chewy consistency.

Microscopic examination revealed a tumor mass consisting of the proliferation of tumor cells in the form of spindles and stellates, with an oval to round nucleus, eosinophilic cytoplasm, mostly scattered, some of which arranged in cord and nest, and partially surround small blood vessels to form vasoformative ring, infiltrative between the myxoid stromal. Mitosis is not found. There is a proliferation of partly dilated blood vessels containing erythrocytes. Also, we found visible erythrocyte extravasation, and distribution of lymphoplasmacytic inflammatory cells, neutrophil polymorphonuclear cells, and hemosiderophage (Figure 1).
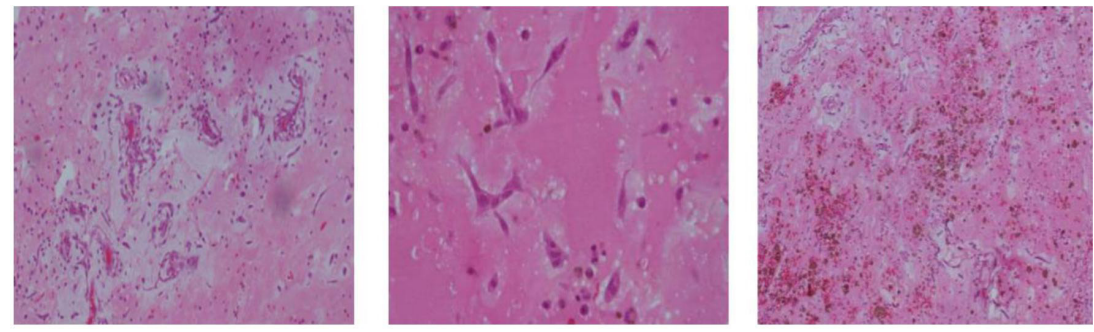

A

B

$\mathrm{C}$

Figure 1 A. Tumor cells mostly scattered, partially form cord, nest, and vasoformative ring, infiltrative in the myxoid stroma (H\&E, 100x) B. Spindle and stellate shape of the tumor cells (H\&E, 400x) C. Distribution of lymphoplasmacytic inflammatory cells, neutrophil polymorphonuclear cells, and hemosiderophage (H\&E, 40x)

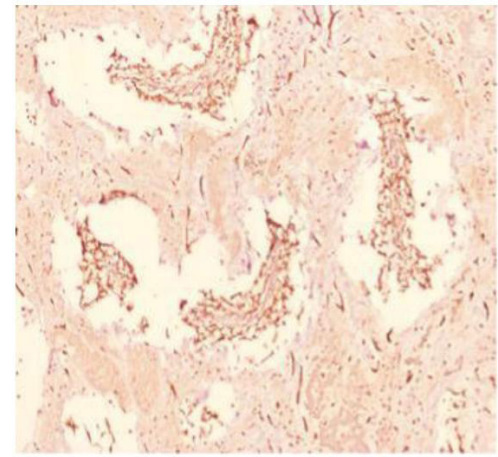

A

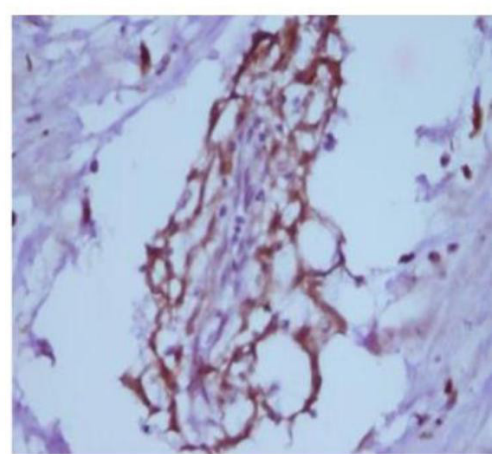

B
Figure 2 A. Strong and diffuse positive of the single tumor cells, cord, nest, and vasoformative rings with calretinin immunohistochemical staining (IHC calretinin, 100x). B. Strong positive calretinin in the nucleus and cytoplasm of the tumor cells, but negative in the endothelial cells of the blood vessels (IHC calretinin, 400x)
Immunohistochemical examination for calretinin showed the tumor cells are intensely stained and diffuse positive in the nucleus and cytoplasm of the single tumor cells, cord, nests, and vasoformative rings, but not in the endothelial cells of the blood vessels (Figure 2). Routine hitopathological examination with $\mathrm{H} \& \mathrm{E}$ needs to be confirmed by immunohistochemistry to further confirm the diagnosis. Financially and culturally there were no obstacles.

Based on the clinical finding, echocardiography, macroscopic, microscopic, and immunohistochemical examinations, the patient was diagnosed as cardiac myxoma in the left atrium. The cardiac myxoma was a benign tumor without oncological stagging.

\section{DISCUSSION}

Cardiac myxoma is the most common benign primary heart tumor in adults with an incidence of 0.5-1.0 cases per million population per year. These tumors are three times more common in women than men in the fourth to seventh decades of life and are rarely found in children., ${ }^{1,2,3}$

The location of myxoma of the heart is most often in the left atrium (60-80\%), in the interatrial septum and fossa ovalis, the right atrium (15$28 \%$ ), and the right ventricle (3-4\%). About $10 \%$ of cardiac myxoma has also been reported as biatrial. The clinical manifestation of cardiac myxoma varies depending on the location of the tumor, size, shape, mobility, and growth rate. As many as $10-20 \%$ of cardiac myxomas are asymptomatic. Heart symptoms include syncope, shortness of breath, chest pain, and palpitations, whereas non-specific symptoms such as weakness, fever, weight loss, and loss of appetite. Most of the signs in the heart are related to tumors that impede normal blood flow through the heart, either intermittently or throughout the cardiac cycle. ${ }^{1,2,3,4}$ In this case, the patient was a 49-year-old woman with frequent palpitations and shortness of breath during strenuous activity and often feel weak.

An essential examination in diagnosing cardiac myxoma is echocardiography. Transthoracic echocardiography is the diagnostic modality of choice for cardiac myxoma. On echocardiography examination, cardiac myxoma appears as a mobile endocardial mass with an irregular shape, most often originating from the left atrium in the fossa ovalis. More sophisticated echocardiography, such as three-dimensional and contrast-enhanced echocardiography, can provide complete characteristics of the tumor, size, and location. Also, this examination modality can describe tumor adhesion, homogeneity, vascularization, and calcification. If the stalk of 
the tumor is not visible, CT and MRI examinations can help to exclude myocardial infiltration that is found in the malignant process. ${ }^{5,6,7,8}$ In this case, an echocardiographic test was performed and found a mass in the left atrium attached to the intra atrial septum with $4.97 \times 2.83 \mathrm{~cm}$ in size. The conclusion is mass in the left atrium suspected of myxoma.

About $90 \%$ of cardiac myxomas occur sporadically, and about $5-10 \%$ are familial and are associated with the Carney complex. This autosomal dominant hereditary disease occurs due to mutations in the PRKAR1A gene located on chromosome 17q22-q24. The Carney complex diagnosis is based on the presence of 2 major criteria or one major criterion and one additional criterion. Major criteria consist of: cardiac myxoma, another myxoma (such as on the breast, skin or mucosa), spotty skin pigmentation or blue naevus, Cushing's Syndrome, acromegaly, large cell calcifying Sertoli cell tumor, psammomatous melanotic schwannoma, and osteochondromyoma. In contrast, additional criteria consist of: affected first-degree relatives and inactivated mutations of the PRKAR1A gene. Although histologically similar, sporadic myxoma is usually found in middle-aged women as a solitary mass in the left atrium. Whereas familial myxoma is often multicentric at a younger age and does not show preference in women. ${ }^{1,2,6}$

The macroscopic features of cardiac myxoma are quite variable. Tumor size between $1 \mathrm{~cm}$ or $>15 \mathrm{~cm}$. Tumors can have a stalk or not, and the stalk of the tumor is usually long, which allows the tumor to move freely. Two macroscopic subtypes that can be found are solid and villous. Tumors of solid type can be globular or elongated with a smooth, shiny, sometimes undulant surface. Villous type tumor has an irregular shape, often brittle and papillary surface. The surface of the incision varies, usually because of the myxoid tissue and areas of intratumoral bleeding. Myxoid tissue has a mucoid appearance like pearl, white, gray, or yellowish-green. Rare cardiac myxoma shows extensive calcification with a stone-like appearance called lithomyxoma. ${ }^{1,2}$ In this case, the first tissue size was $4.5 \times 3.5 \times$ $1.2 \mathrm{~cm}$, and the second tissue was $2.8 \times 2.3 \times$ $1 \mathrm{~cm}$, irregular shape, with a chewy consistency. On the surface of the cut, section appear brownish, shiny, and smooth.

The microscopic appearance of cardiac myxoma shows a variable feature even in the same tumor. This tumor is characteristic by the presence of cells called myxoma cells or lepidic cells, which are stellate, ovoid, plump spindle cells, with eosinophilic cytoplasm and round or oval nuclei arranged scattered or in clusters. When in clusters, tumor cells can form cord, nests, or rings, namely the tumor cells around the capillaries or small blood vessels, to form vasoformative ring. The tumor cells are present in a myxoid matrix rich in mucopolysaccharides with varying amounts of proteoglycans, collagen, and elastin. The background can contain a large number of inflammatory cells and rarely found multinucleated giant cells. Large vessels with thick walls are often found near the stalk or base of the lesion, while smaller vessels are nearby. New and old bleeding is common and may be caused by vascularity and trauma throughout the cardiac cycle. Prolonged bleeding may manifest as haemosiderin-laden macrophage and/or iron crusts of elastic fibers in the tumor matrix (GamnaGandy body). Fibrosis, cystic changes, necrosis, thrombosis, calcification, and metaplastic bone formation can also be found. ${ }^{1,2,9}$ In this case, the tumor consisting of a proliferation of spindle and stellate cells, with an oval to round nucleus, eosinophilic cytoplasm, most scattered, some form cord, nests, and some other form vasoformative rings, infiltrative between the myxoid stroma. Mitosis is not found. There is a proliferation of partly dilated blood vessels containing erythrocytes-also visible erythrocyte extravasation, and distribution of lymphoplasmacytic inflammatory cells, neutrophil polymorphonuclear cells, and hemosiderophage.

Immunohistochemical examination of cardiac myxoma showed reactivity against calretinin antibody in almost all cases. In contrast, variable reactivity was observed for antibody PGP9.5, neuron-specific enolase, S100 protein, synaptophysin, smooth muscle actin (SMA), and desmin. Myxoma cells are not reactive with epithelial markers and monocytes/ macrophages. Endothelial markers (e.g., Factor VIII, Ulex Europaeus Agglutinin, CD31, CD34, thrombomodulin, and endothelin) positive in endothelial, with varying reactivity, are reported on myxoma cells. ${ }^{1,2,6}$ In this case, the tumor cells appear strong and diffuse positive with immunohistochemical calretinin staining in single scattered, cord, nest, and vasoformative ring tumor cells. Calretinin was firmly and diffuse positive in the nucleus and cytoplasm of tumor cells, but negative in the vascular endothelium cells.

Differential diagnosis of cardiac myxoma includes 1) thrombus, the absence of perivascular spindle and stellate-shaped tumor cells help differentiate myxoma from thrombus, and negative calretinin stains on immunohistochemical examination, 2) papillary fibroelastoma, consists of avascular fibroelastic fronds which are lined by endothelial cells with immunohistochemical CD34/ CD31 positive, and calretinin negative, 3) Sarcoma, differentiate by the evidence of heart muscle infiltration, pleomorphism, necrosis and mitosis, positive smooth muscle actin, and negative calretinin, 4) Haemangioma, consist of 
various sizes blood vessels, and a positive CD34/ CD31 examination, whereas calretinin negative, 5) Rhabdomyoma, consist large vacuole cells with clear cytoplasm and abundant glycogen (spider cells), with positive myoglobin, desmin, actin, and vimentin 6) Metastasis of an adenocarcinoma, the infiltration of malignant glandular cells, with positive immunohistochemical examination depending on the location of the primary tumor. ${ }^{1,2}$

The choice of treatment for cardiac myxoma is surgical resection. For tumors larger than $1 \mathrm{~cm}$ in size, surgical resection should be performed immediately to prevent the risk of embolization..$^{1,6,10,11,12}$ In this case, surgical resection of the tumor was performed.

The prognosis for cardiac myxoma is excellent after surgical excision. However, recurrence of intracardiac after surgical excision is found in $12-22 \%$ of familial cardiac myxoma and $1-4 \%$ in sporadic cases. ${ }^{1,2,12}$ The last condition of the patient in this case at the time of control was in good condition and able to carry out daily activities as usual.

\section{CONCLUSION}

Primary tumors of the heart are scarce. Cardiac myxoma is a benign primary heart tumor that is most often found compared to other benign tumors. This case was diagnosed as cardiac myxoma based on clinical features, echocardiography, macroscopic, histopathology, and immunohistochemical examinations. The choice of treatment for this case is by surgical resection, and the patient's prognosis is excellent.

\section{CONFLICT OF INTEREST}

There is no conflict of interest regarding the manuscript.

\section{FUNDING}

None.

\section{AUTHOR CONTRIBUTION}

I Gusti Ayu Sri Mahendra Dewi is responsible for the study from the conceptual framework.

\section{ACKNOWLEDGMENT}

The author is very grateful to Ni Putu Ekawati, Ni Made Mahastuti, and Kadek Agus Suhardinata Putra for their assistance, input, and suggestions on this manuscript.

\section{REFERENCES}

1. Singhal P, Luk A, Rao V, Butany J. Molekular basis of cardiac myxomas. Int J Mol Sci. 2014;15(1):1315-1337 DOI: 10.3390/ijms15011315

2. Jain D, Maleszewski JJ. Cardiac Myxoma. In: Travis WD, Brambilla E, Burke AP, Marx A, Nicholson AG, editors. WHO classification of tumours of the lung, pleura, thymus and heart, $4^{\text {th }}$ edition. Lyon: IARC. 2015;311-314.

3. Hendrick EL, Edyta CP. Tumors of the heart. In: Kumar, Abbas, Aster, editors. Robbins and Cotran Pathologic Basis of Disease, $9^{\text {th }}$ edition. Philadelphia: Elsevier. 2015;575-576.

4. Ordonez, Rosai J. Cardiovascular System. In: Rosai J, editor. Rosai and Ackerman's Surgical Pathology, $10^{\text {th }}$ edition. Philadelphia: Elsevier. 2011;2278-2279.

5. Mankad R, Herrmann J. Cardiac tumors: echo assessment. Echo Res Pract. 2016;3(4):65-77 DOI: 10.1530/ ERP-16-0035

6. Boutayeb A, Mahfoudi L, Moughil S. Atrial Myxoma: From Diagnosis to Management. Clinics in Surgery. 2017:1-8 http://clinicsinsurgery.com

7. El Sabbagh A, Al-Hijji M, Thaden JJ, Pislaru SV, Pislaru CD, Pellikka P, Arruda-Olson AM, Grogan M, Greason KL, Maleszewski J, Klarich KW, Nkomo VT. Cardiac Myxoma: The Great Mimicker. JACC: Cardiovascular Imaging. 2017;10(2):203-206. 10.1016/j.jcmg.2016.06.018

8. Ali R, Tahir A, Nadeem M, Rizvi SB. A Silent Left Atrial Myxoma: A Rare Benign Cardiac Tumor. Cureus. 2018;10(4):2551 DOI: 10.7759/cureus.2551

9. Rahman T, Ali Z, Kabir H, Azam A, Majumder AAS, Rahman A, Haque SA. Clinical profile of cardiac myxoma: 11 years' experience of 90 cases. Bangladesh Heart Journal. 2016;31(3):18-22.

10. Karabinis A, Samanidis G, Khoury M, Stavridis G, Perreas K. Clinical presentation and treatment of cardiac myxoma in 153 patients. Medicine. 2018;97(37):12397 DOI: 10.1097/MD.0000000000012397

11. Khan MF, Fa XE, Diagnosis and treatment of Cardiac Myxoma-Short Term Clinical Analysis of 14 Cases in a Single Hospital. Biol Med. 2016;8(5):2-4 DOI: 10.4172/0974-8369.1000314

12. Nehaj F, Sokol J, Mokan M, Jankovicova V, Kovar F, Kubaskova M, Mizera S, Mokan M. Outcomes of Patients with Newly Diagnosed Cardiac Myxoma: A Retrospective Multicentric Study. BioMed Research International. 2018;15. https://doi.org/10.1155/2018/8320793

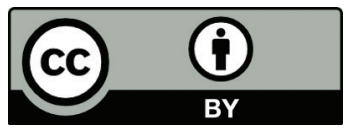

This work is licensed under a Creative Commons Attribution 